\title{
Academic Buoyancy, Student Achievement, and the Linking Role of Control: A Cross-Lagged Analysis of High School Students
}

\author{
Rebecca J. Collie and Andrew J. Martin \\ School of Education, University of New South Wales, Australia \\ Lars-Erik Malmberg and James Hall \\ Department of Education, University of Oxford \\ Paul Ginns \\ Faculty of Education and Social Work, University of Sydney
}

September 2014

Requests for further information about this investigation can be made to Professor Andrew J. Martin, School of Education, University of New South Wales, NSW 2052, AUSTRALIA. E-Mail: andrew.martin@unsw.edu.au. Phone: +61 29385 1952. Fax: +61 293851946.

The authors would like to thank the Australian Research Council for funding this research. 


\title{
Academic Buoyancy, Student Achievement, and the Linking Role of Control:
}

\section{A Cross-Lagged Analysis of High School Students}

\begin{abstract}
Background. Previous research has indicated that although academic buoyancy and student achievement are associated, the relationship is relatively modest.

Aims. We sought to determine whether another construct might link academic buoyancy and student achievement. Based on prior theoretical and empirical work, we examined a sense of control as one possible linking mechanism.
\end{abstract}

Sample. The study analysed data from 2,971 students attending 21 Australian high schools.

Methods. We conducted a cross-lagged panel design as a first means of disentangling the relative salience of academic buoyancy, control, and achievement (Phase 1). Based upon these results, we proceeded with follow-up analyses of an ordered process model linking the constructs over time (Phase 2).

Results. Findings showed that buoyancy and achievement were associated with control over time, but not with one another (Phase 1). In addition, control appeared to play a role in how buoyancy influenced achievement and that a cyclical process may operate among the three factors over time (Phase 2).

Conclusion. The findings suggest that control may play an important role in linking past experiences of academic buoyancy and achievement to subsequent academic buoyancy and achievement.

Keywords: academic buoyancy; control; academic achievement; cross-lagged analysis

Running head: Academic buoyancy, achievement, and control 


\section{Academic Buoyancy, Student Achievement, and the Linking Role of Control:}

\section{A Cross-Lagged Analysis of High School Students}

An emphasis on students' cognitive development and achievement has long been the focus of formal education. At the same time, scholars, educators, and policy-makers are becoming increasingly aware of the importance of education for addressing social-emotional development (Durlak, Weissberg, Dymnicki, Taylor, \& Schellinger, 2011; Greenberg et al., 2003). Indeed, social-emotional development is increasingly viewed as a central part of schooling in order to help students develop skills that can assist them in navigating the challenges of life (Durlak et al., 2011). Part of this social-emotional development involves students being able to effectively navigate adversity and setback, including that which occurs within the academic domain (Martin \& Marsh, 2009). Martin and Marsh (2009) argued that such adversity can be major and substantial (e.g., expulsion, learning disability) or relatively low-level and 'everyday' (e.g., occasional poor result, study stress). They suggest that academic resilience is the personal attribute relevant to navigating substantial adversity and academic buoyancy is the personal attribute relevant to navigating everyday adversity (Martin, 2013). Whereas academic resilience pertains to a relatively small group of students (though, essential to support), academic buoyancy pertains to all students because of the ever-present low-level challenges of everyday academic life (Martin \& Marsh, 2009). This study investigates academic buoyancy as it focuses on whole-school populations and everyday academic adversity (but see Martin, 2013 for recent work into academic resilience).

\section{Academic Buoyancy and Student Achievement}

Research has demonstrated that students' ability to be buoyant in the face of academic challenge and setback is associated with important motivational (e.g., greater persistence; Martin, Colmar, Davey, \& Marsh, 2010) and emotional (e.g., lower anxiety; Martin, Ginns, Brackett, Malmberg, \& Hall, 2013; Putwain, Conners, Symes, \& Douglas-Osborn, 2012; Putwain \& Daly, 2013) outcomes. Importantly though, buoyancy is different from these motivational and emotional constructs. For example, buoyancy refers to an appraisal of responses to past adverse experiences 
that are general in nature, whereas the motivational construct of self-efficacy refers to a sense of agency in relation to future experiences that are task-specific (Bandura, 2001). Moreover, buoyancy refers to an appraisal of one's capacity to deal with setback, whereas emotions relate to a set of psychological processes that are experienced in response to an event (e.g., fear, worries, impulses to act; Pekrun et al., 2011; Weiner, 2010).

Despite the demonstrated positive effects of buoyancy on motivational and emotional factors (e.g., Martin et al., 2013), a question remains concerning buoyancy's relationship with achievement. Martin (2014) examined a direct relationship between buoyancy and achievement and found a significant association; however, effect sizes were generally small. This is intriguing given that academic buoyancy is associated with processes that are themselves linked with student achievement (e.g., motivation; Martin et al., 2010). In the current study, we are interested in advancing understanding of the buoyancy construct by looking more closely at its relationship with student achievement. More precisely, we explore whether this association is direct or works via an indirect mechanism. The latter was postulated due to emerging research that has suggested these are possible. For example, Putwain and Daly (2013) investigated the relationship between buoyancy and achievement in association with anxiety, finding that those high in buoyancy and low in anxiety evinced high achievement whereas those higher in anxiety scored lower. In our study, we seek to add to the buoyancy literature by exploring the roles played by additional factors.

There are numerous theories relevant to human functioning in the face of adversity. Many of these, in one form or another, posit control as a pivotal factor in navigating adversity (e.g., Connell, 1985; Heckhausen, Wrosch, \& Schulz, 2010; Skinner, 1996; Weiner, 2010). Following recent work investigating the issue of control and adversity (e.g., Heckhausen et al., 2010; Liem \& Martin, 2013), the current study harnesses the construct of control as defined by students' sense that they are able to control future (negative or positive) academic outcomes. In terms of academic achievement, we suggest that attribution theory (Weiner, 2010) has contributed strongly to understanding of the control construct — though we recognize that more recent frameworks such as 
self-determination theory also centrally position control in relation to achievement (via competence; Skinner, 1996; Ryan \& Deci, 2000). As discussed below, by referring to attribution theory (Weiner, 2010) and prior research that has linked buoyancy and achievement with control, albeit in separate studies (e.g., Liem \& Martin, 2012), we feel there is support for an examination of buoyancy, control, and achievement with particular interest in the ordering of factors.

\section{The Role of Control}

According to attribution theory, motivated action is influenced by causal ascriptions that individuals place upon prior outcomes (Weiner, 2010). When a particular outcome occurs, individuals attempt to understand why. For example, students may conclude that they failed a test (an outcome) because they lack the ability to do the subject (a causal ascription). Once made, these ascriptions then influence an individual's feelings and actions (known as psychological and behavioral consequences) and, in turn, future outcomes (where the cycle may begin again). If students experience a prior outcome that was undesired it is likely they will attempt to alter the perceived causes (through behavioral consequences) to produce a more desirable outcome next time (Weiner, 2010). However, this is dependent upon three causal dimensions: locus, stability, and controllability (Weiner, 2010).

The definition of control used in the current study concerned a student's sense of being able to control future academic outcomes. This intersects two key dimensions of attribution theory: (internal) locus and controllability. The extent to which individuals perceive a prior outcome as internal and controllable influences subsequent actions (Wiener, 2010; see also Skinner, ZimmerGembeck, \& Connell, 1998). For example, if students attribute an academic setback to something internal and controllable (such as not studying enough), then they are more likely to attempt to alter the cause (i.e., by studying harder next time) to avoid a repetition of the outcome. In contrast, if the cause of the academic setback is perceived as being external and/or uncontrollable (such as poor teaching), students may feel there is nothing they can do to change the outcome next time. Thus, they may not change their approach to schoolwork in the face of another upcoming challenge. 
Given the evidence regarding a modest link between buoyancy and achievement (Martin, 2014) and following recent work suggesting that other factors may help explain this association (Putwain \& Daly, 2013), we investigate whether a sense of control over outcomes (incorporating both internal locus and controllability) functions as a linking mechanism in the association between buoyancy and achievement. This is based on understanding from attribution theory (Weiner, 2010) where we position academic buoyancy and achievement as prior outcomes that influence subsequent causal ascriptions. This corresponds with Weiner's (2010) identification of an outcome as a success or failure. In this case, prior achievement and 'successfully navigating a setback' (i.e., academic buoyancy) are viewed as successful past outcomes from which causal ascriptions such as effort (a control-relevant attribution) are made. For example, if a student successfully navigates a setback like a low test score, he or she likely experiences a sense of internal locus and controllability that are well-established foundations for subsequent achievement (Bandura, 2001; Skinner, 1996; Weiner, 2010). As relevant to our investigation then, academic buoyancy and achievement predict control.

Notwithstanding this, as per Weiner's model, there is a cycle such that control-relevant factors give rise to emotional (e.g., pride) and behavioral (e.g., greater effort) consequences which in turn predict subsequent adaptive outcomes (e.g., subsequent achievement and reduced likelihood of academic setback, or buoyancy). Given this st tested such that we not only explore buoyancy and achievement predicting control, but also this control predicting subsequent buoyancy and achievement.

In addition to theoretical support, empirical research also highlights the relevance of control for both buoyancy and achievement. More precisely, research has shown that buoyancy is associated with control (Liem \& Martin, 2012; Martin \& Marsh, 2006; Martin et al., 2010), and that control is associated with achievement (Liem \& Martin, 2012; Marsh, Hau, Artelt, Baumert, \& Peshar, 2006; Ross \& Broh, 2000; Skinner, Wellborn, \& Connell, 1990; You, Hong, \& Ho, 2011). 
To date, however, no research has examined all three constructs concurrently to ascertain whether there is a process occurring that includes control.

\section{Overview of Current Study}

In an attempt to better understand the construct of buoyancy and factors that may help explain the association between buoyancy and achievement, we examine the possibility of a variable linking the two constructs. With support from attribution theory (Weiner, 2010) and recent research (e.g., Liem \& Martin, 2012; Martin et al., 2010), we test control as a linking construct. In Phase 1 of the analyses, we implement a classic cross-lagged panel design (e.g., Huck, Cormier, \& Bounds, 1974) as a first means of disentangling the relative salience of buoyancy, control, and achievement (see Figure 1). Because the findings from cross-lagged panel designs can guide researchers' decisions about the ordering of factors in a process, we then use Phase 1 findings alongside attribution theory as a basis to explore a more structured ordering of the three constructs across time (Phase 2). Taken together, we consider the present study as something of a sequenced empirical investigation that seeks to tease out processes relevant to buoyancy, control, and achievement.

\section{Method}

\section{Participants and Procedure}

Participants were 2,971 students from 21 secondary schools in major urban areas of Australia. Students completed a survey at Time 1 (term one, in 2010) and Time 2 (one year later in 2011). At Time 1, participants were in Grade 7 (16\%), Grade 8 (24\%), Grade 9 (27\%), Grade 10 (19\%), or Grade 11 (14\%). Schools were independent or Catholic co-educational (10 schools), single-sex girls (6 schools), or single-sex boys ( 5 schools) schools. They were representative of a variety of achievement levels (though generally higher in achievement and socio-economic status [SES] than the national average). Slightly more than half of the participants (52\%) were male and they had an average age of 13.8 years $(S D=1.29$, range $11-18$ years $)$ at Time 1 and 14.9 years $(S D=1.30$; range 12-19 years) at Time 2. The vast majority of participants (90\%) had an English speaking 
background. At the two waves of data collection, the classroom teacher administered the instrument in class. The teacher explained each of the scales and provided a sample item. Students were asked to complete the instrument by themselves, to request help if needed, and to provide only one answer for each item. These data are the integration of common variables (buoyancy, control, achievement) from two projects: one investigating the effects of boarding school $(N=2002$; Martin, Papworth, Ginns, \& Liem, 2014) and one investigating the role of adaptability and personal best goals in academic and non-academic outcomes $(N=969$; Martin, in press; Martin, Nejad, Colmar, \& Liem, 2013).

\section{Measures}

All measures were included in one survey. Demographic items were presented first, followed by a self-report of prior achievement, buoyancy, and control items. Table 1 presents descriptive data, factor loadings from our baseline CFA, and Cronbach's alphas. Skewness values were between -.71 and .63, and kurtosis values were between -.97 and -.13, indicative of approximate normality of all indicators.

Academic buoyancy. The Academic Buoyancy Scale (ABS; Martin \& Marsh, 2008) comprises four items ("I'm good at dealing with setbacks at school - e.g., negative feedback on my work, poor result"; "I don't let study stress get on top of me"; "I think I'm good at dealing with schoolwork pressures"; "I don't let a bad mark affect my confidence"). Respondents rated items from 1 ('Strongly Disagree') to 7 ('Strongly Agree'). Prior research has provided evidence of the scale's unidimensionality, approximately normal distribution, invariance as a function of age, gender and ethnicity, internal consistency, and associations with other educational processes and outcomes (Martin et al., 2010; Martin \& Marsh, 2008; Putwain et al., 2012).

Control. Control is operationalized via the 4-item 'uncertain control' factor from the Motivation and Engagement Scale - High School instrument (MES-HS; Martin, 2010). This scale assesses students' sense of control and uncertainty/certainty about how to do well or how to avoid doing poorly at school and in schoolwork (“When I get a good mark I'm often not sure how I'm 
going to get that mark again"; "When I don't do so well at school I'm often unsure how to avoid that happening again"; "When I get a bad mark I'm often unsure how I'm going to avoid getting that mark again"; "I'm often unsure how I can avoid doing poorly at school"). The items were designed to tap into both locus and controllability (Martin, 2007). Prior measurement work on the scale has provided evidence of normality, reliability, and differentiation from other constructs in the MES-HS (e.g., Green, Martin, \& Marsh, 2007; Liem \& Martin, 2012; Plenty \& Heubeck, 2011, 2013; Nagabhushan, 2013). Students rated themselves on a scale of 1 ('Strongly Disagree') to 7 ('Strongly Agree'). To facilitate interpretation in the present study, the factor is reversed such that higher scores reflect greater control (and less uncertainty).

Achievement. Students were asked for their results from a nation-wide, standardized test of literacy and numeracy (National Assessment Program in Literacy and Numeracy) administered by the Australian Curriculum and Assessment and Reporting Authority. We make the assumption that students' self-reported prior achievement closely reflects their actual prior achievement. This is based on Hattie's (2009) work, which demonstrated that such self-reports are correlated very strongly with students' actual achievement. In addition, actual achievement data were collected from a sub-sample in this program of research and we found no significant difference between actual achievement and self-reported numeracy, $t(339)=0.45, p=.654$ and literacy, $t(340)=0.17$, $p=.868$. Students received their test results several months prior to filling out the questionnairethe time differed depending on what grade the students were in at Time 1 and ranged from 6 to 18 months prior. Given this is a bi-annual test, some students had not received a Time 2 achievement score at the time of the second survey and so their Time 2 achievement data were set as missing. In the present study, a latent achievement factor was estimated using students' self-reported literacy and numeracy scores.

Socio-demographic covariates. Data were also collected on socio-demographic characteristics including gender, age, language background, parent education, and parent socioeconomic status (SES). On language background, participants were asked if they spoke only 
English (0) and/or another language (1) at home. Gender was coded 0 for females and 1 for males. Age (years) was retained as a continuous variable. Students' SES was determined from their home postcode using the Australian Bureau of Statistics relative advantage/disadvantage index, with higher scores reflecting higher SES. A latent parent education factor was estimated based on female and male caregiver education indicators.

\section{Statistical Analysis}

Using Mplus version 7.0 (L. K. Muthén \& B. O. Muthén, 2012), a series of analyses examined the relative salience of $\mathrm{T} 1$ buoyancy, $\mathrm{T} 1$ control, and $\mathrm{T} 1$ achievement in statistically predicting buoyancy, control, and achievement at T2. The first component of analyses (Phase 1) employed a cross-lagged panel design. This allows researchers to disentangle and delineate the viability and strength of competing 'directional' interpretations between constructs that are measured at two different times (Huck et al., 1974).

The second set of analyses (Phase 2) was based on the results from the cross-lagged panel analyses. These aimed to use the cross-lagged panel findings to stipulate more nuanced relational processes across time. Subsidiary analyses also explored indirect effects of T1 achievement and buoyancy on T2 achievement and buoyancy via control at T1. Indirect effects were based on bootstrapped standard errors (with 1000 draws; MacKinnon, Lockwood, Hoffman, West, \& Sheets, 2002).

Confirmatory factor analysis (CFA) and structural equation modeling (SEM) were used in both phases and measured buoyancy, control, and achievement as latent factors (i.e., purged of random measurement error). Correlated uniquenesses for parallel items at $\mathrm{T} 1$ and $\mathrm{T} 2$ were included in the SEMs to account for within-person dependencies. Thus, in order to get accurate estimates of the relationships among the focal constructs, correlations among uniquenesses needed to be included in the statistical models (Marsh, Balla, \& Hau, 1996). In the SEMs, socio-demographics were included as predictors of all Time 1 and Time 2 buoyancy, control, and achievement factors, thereby controlling for variance attributable to socio-demographics. 
The root mean square error of approximation (RMSEA) and the comparative fit index (CFI) were used as indicators of model fit. RMSEAs at or less than .08 and .05 reflect adequate and good fits respectively; CFIs at or greater than .90 and .95 reflect adequate and good fits respectively (McDonald \& Marsh, 1990). Maximum likelihood (L. K. Muthén \& B. O. Muthén, 2012) was used to estimate our statistical models. Given less than five percent of substantive data were missing, these were estimated using the Expectation Maximization Algorithm in LISREL 8.80 (Jöreskog \& Sörbom, 2006). Relatively more data from socio-demographic covariates were missing (14.5\%) and we imputed these data using full information maximum likelihood (with Mplus 7.0; L. K. Muthén \& B. O. Muthén, 2012).

\section{Results}

\section{Preliminary Descriptive and Measurement Analyses}

We used CFA to test measurement properties underlying the structural model. This yielded an excellent fit to the data, $\chi^{2}=1053.54, d f=238, \mathrm{CFI}=.96, \mathrm{RMSEA}=.034$. Factor loading ranges from the CFA are shown in Table 1; these are generally high, significant, and provide a sound measurement base for conducting cross-lagged and other analyses - the focus of the study. Table 2 presents correlations from the CFA. As we can see, there was relative stability over time for our three key repeated measures: buoyancy $(r=.59)$, achievement $(r=.57)$ and control $(r=.59)$.

\section{Phase 1: Cross-lagged Panel Analyses}

In our cross-lagged model, we constrained factor loadings of repeated items to be equal across the two time-points to ensure invariance of the repeated measures. Results from the cross-lagged analyses (see Figure 2) demonstrated that the data fitted the model well, as shown by excellent fit indices, $\chi^{2}=1053.54, d f=238, \mathrm{CFI}=.96$, RMSEA $=.034 . \mathrm{T} 1$ and T2 auto-lagged parameters were strong and significant (see Figure 2) — suggesting a notable amount of unique variance attributable to cross-lagged parameters. Beyond the variance explained by T1 buoyancy and sociodemographics, T1 control was a significant predictor of T2 buoyancy $(\beta=.05, p<.05)$ and beyond variance explained by $\mathrm{T} 1$ control and socio-demographics, T1 buoyancy was a significant predictor 
of T2 control $(\beta=.06, p<.01)$. In addition, beyond the variance explained by $\mathrm{T} 1$ achievement and socio-demographics, T1 control was a significant predictor of T2 achievement $(\beta=.23, p<.001)$ and beyond variance explained by $\mathrm{T} 1$ control and socio-demographics, T1 achievement was a significant predictor of $\mathrm{T} 2$ control $(\beta=.11, p<.001)$. Notably, there were no statistically significant cross-lagged relationships between buoyancy and achievement.

\section{Phase 2: Modified Model}

Given the central role played by control in linking to both buoyancy and achievement in the cross-lagged relationships, given that buoyancy and achievement shared no cross-lagged variance, and given propositions under Weiner's (2010) attribution process (see Introduction), we explored a process model in which control is a linking construct such that T1 buoyancy and T1 achievement predicted T1 control, T1 control predicted T2 buoyancy and T2 achievement, which in turn predicted T2 control (see Figure 3). That is, if T1 buoyancy and achievement are related to control and control is related to T2 buoyancy and achievement, there is a case for exploring control as a linking factor. This model yielded an excellent fit: $\chi^{2}=1053.54, d f=238, \mathrm{CFI}=.96, \mathrm{RMSEA}=$ .034. Results shown in Figure 4 reveal that $\mathrm{T} 1$ buoyancy predicts $\mathrm{T} 1$ control $(\beta=.37, p<.001), \mathrm{T} 1$ achievement predicts T1 control $(\beta=.29, p<.001)$, T1 control predicts T2 buoyancy $(\beta=.05, p<$ $.05)$ and $\mathrm{T} 2$ achievement $(\beta=.23, p<.001), \mathrm{T} 2$ buoyancy and $\mathrm{T} 2$ achievement predict $\mathrm{T} 2$ control $(\beta=.30, p<.001$ and $\beta=.11, p<.01$, respectively). In addition, T1 buoyancy predicts $\mathrm{T} 2$ control $(\beta=.10, p<.001)$, but T1 achievement has no significant predictive role on T2 control.

Subsidiary analyses tested indirect effects of $\mathrm{T} 1$ achievement and buoyancy on $\mathrm{T} 2$ achievement and buoyancy via T1 control and also T1 control on T2 control via T2 buoyancy and achievement using bootstrapping (1000 draws). This model demonstrated excellent fit: $\chi^{2}=$ $1070.05, d f=242, \mathrm{CFI}=.96, \mathrm{RMSEA}=.034$. We found significant indirect effects between T1 achievement and T2 buoyancy via T1 control $(\beta=.02 ; p<.01)$, between T1 buoyancy and T2 achievement via $\mathrm{T} 1$ control $(\beta=.08 ; p<.001)$, between $\mathrm{T} 1$ and $\mathrm{T} 2$ achievement via $\mathrm{T} 1 \mathrm{control}(\beta=$ $.06 ; p<.001)$, between T1 and T2 buoyancy via T1 control $(\beta=.02 ; p<.01)$, between T1 and T2 
control via T2 buoyancy $(\beta=.02 ; p<.01)$ and T2 achievement $(\beta=.04 ; p<.001)$. In addition, a subsequent model that included direct paths from T1 buoyancy to T2 achievement and from T1 achievement to $\mathrm{T} 2$ buoyancy showed that these parameters were not significant, further signaling that the relationship between $\mathrm{T} 1$ and $\mathrm{T} 2$ buoyancy and achievement seems to operate via control.

\section{Discussion}

Phase 1 findings suggested that control was associated with both T1 and T2 buoyancy and achievement, but that the latter two constructs were not connected across time (see Figure 2). It was then speculated that control may be a linking construct, connecting buoyancy and achievement. This suggested a process model in which $\mathrm{T} 1$ buoyancy and $\mathrm{T} 1$ achievement predict control and control predicts T2 buoyancy and T2 achievement (see Figure 3). Accordingly, Phase 2 showed that the relationship between T1 and T2 buoyancy and achievement may be partly explained by control (see Figure 4). Taken together, our findings help show one means by which buoyancy is associated with achievement. The significance of this finding is underscored by the fact that buoyancy was not directly associated with achievement in Phase 1. Thus, the findings advance knowledge about the emerging construct of buoyancy as relevant to achievement—an area that has yielded some mixed findings to date. Importantly, then, the study helps to reveal a boundary condition of the constructbuoyancy does not appear to link directly with achievement, but does so indirectly via control. Hence, research incorporating both buoyancy and achievement ought to be mindful of this nuance. We also make the point that by understanding the different strengths of associations between buoyancy and other constructs, we come to a greater understanding of what buoyancy is and is not. Thus, the present findings can be located in an ongoing program of research that seeks to understand the precise means by which buoyancy connects to major constructs on the psychoeducational landscape. This is also the first time buoyancy and achievement have been located in a well-established theoretical process model (viz. Weiner, 2010) and this attributional perspective has been critical in assisting our understanding of why buoyancy impacts achievement as it has done.

Key findings from the two phases of data analysis are discussed below. 


\section{Phase 1 Analysis Findings}

The most pertinent finding of Phase 1 was that academic buoyancy and achievement were not associated with one another over time. Instead, at T1 they predicted and at T2 they were predicted by control at $\mathrm{T} 2$ and $\mathrm{T} 1$ respectively. This finding suggests that in themselves, prior experiences of buoyancy and achievement may not be enough to predict subsequent achievement and buoyancy respectively. Perhaps this occurs because prior achievement or success in navigating a setback may or may not activate the necessary adaptive actions that are required for future success. The extent to which these adaptive actions are taken may hinge on other processes. For example, buoyancy may help to activate other processes that are more closely associated with achievement. This interpretation is consistent with prior research showing that buoyancy is relevant to successfully dealing with social-emotional and motivation factors that are known to predict achievement (Martin et al., 2013; Putwain et al., 2012). Thus, as suggested above and consistent with recent research (Putwain \& Daly, 2013), the extent to which buoyancy promotes achievement may be due to the presence of other factors that link the two constructs. Following the significant linking role of control in the cross-lagged design, this was further examined in Phase 2 analysis.

\section{Phase 2 Analysis Findings}

Linking buoyancy and achievement. Phase 2 supported our speculation that control plays a linking role between buoyancy and achievement. When students had a positive experience such as successfully navigating a challenge or gaining a high mark, this was related to a greater sense of control over future academic outcomes. This additional sense of control, in turn, was then linked to a greater capacity to navigate setback and obtain higher achievement in the future. These findings were supported by the significant direct and indirect effects to and from buoyancy and achievement via control in the process model (Figure 4). Importantly, these effects were tested over time and through indirect effects (bootstrapping), thus, they provide reasonable support for the contended role of control in linking buoyancy and achievement. 
Past theoretical and empirical work suggests that control might connect prior and subsequent buoyancy and achievement because it helps to influence the ensuing actions that individuals undertake. As described above, if an individual feels a sense of control, then they are more likely to take specific, motivated actions in relation to upcoming events (Weiner, 2010). Thus, it is conceivable that buoyancy and achievement are linked by control to the extent that it helps to promote actions — which can be adaptive (e.g., persisting with homework longer) or not (e.g., giving up) depending on the amount of perceived control.

It is well-documented that control is related to achievement (e.g., Liem \& Martin, 2012; Marsh et al., 2006; Ross \& Broh, 2000; Skinner et al., 1990; You et al., 2011). Our finding of control as a variable linking buoyancy and achievement may provide insight into why previous research has related buoyancy with motivational constructs that are known to be associated with achievement (e.g., Caprara, Vecchione, Alessandri, Gerbino, \& Barbaranelli, 2011; Hattie, 2009) such as persistence (e.g., Martin \& Marsh, 2006) and self-efficacy (e.g., Caprara, Vecchione, Alessandri, Gerbino, \& Barbaranelli, 2011; Martin \& Marsh, 2008), but has found a more modest direct relationship between buoyancy and achievement (Martin, 2014). Namely, perhaps buoyancy is associated with motivational constructs like self-efficacy and persistence because they inherently have a level of control associated with them (Skinner, 1996). Thus, it may be that an accompanying sense of control plays an important role in determining outcomes of buoyancy such as achievement. Following from Putwain and Daly's (2013) work identifying (low) anxiety as another factor important in explaining the relationship between buoyancy and achievement, the present finding also broadens current understanding of buoyancy in relation to control.

For educators, our finding of control as a linking variable supports existing work on the essential role that control plays in student outcomes (e.g., academic engagement, Liem \& Martin, 2012; self-efficacy, Martin et al., 2010). In addition, our finding suggests that a sense of control is pivotal in determining whether setback will translate to future positive outcomes. When this is coupled with an ability to navigate challenge (buoyancy), the effects on achievement appear to be 
greater still. Potential approaches to guide the promotion of a sense of control include: the promotion of growth mindsets for learning (Dweck, 2006; Dweck \& Master, 2009), which focus on students' capacity to change their abilities and outcomes; autonomy-supportive learning environments (Deci \& Ryan, 1985, 2012; Reeve \& Jang, 2006), which help to promote a sense of competence; and encouraging students to focus on what academic factors they can control (e.g., effort, strategy, and attitude), which assist their sense of empowerment in the academic process (Martin et al., 2010).

Concurrent effects of academic buoyancy and achievement. We found that the links from buoyancy and achievement to control were concurrent - there was no evidence of the primacy of one of the constructs. Perhaps this occurred because buoyancy and achievement both hold important weight in determining how a student responds in the future. This claim is supported by attribution theory's premise that causal ascriptions placed on any prior outcome can influence subsequent actions and, in turn, future outcomes (Weiner, 2010). It is also possible that the concurrent links reflect the recurring nature of academic challenge (relevant to buoyancy) and achievement, which occur regularly across school days and weeks.

The importance of prior success for academic motivation (e.g., Bandura, 1989, 2006; Deci \& Ryan, 2012) and achievement (e.g., Hattie, 2009) is well-established in the literature. Our finding of the concurrent importance of achievement and buoyancy for future positive outcomes contributes to this understanding by referring to a broader idea of academic 'success.' Importantly, our finding suggests that 'successful' experiences can be diverse in nature - they can involve success in relation to achievement or in navigating academic setback. What appears to be the case is that the opportunity to experience some type of success (whether in relation to buoyancy or achievement) may promote a sense of control and subsequent positive outcomes.

Ongoing cyclical process. Our indirect effects revealed that control was a significant mechanism in determining how buoyancy and achievement were associated. In addition to the tests to and from buoyancy and achievement via control (discussed above), this also included tests to and 
from control (at T1 and T2) via buoyancy and achievement (at T2). Given that these indirect effects were tested across time, they provide evidence that a cyclical process may be taking place.

In addition to the educational strategies for promoting a sense of control described above, there also appears to be benefits in addressing buoyancy and achievement in interventions. For buoyancy, Morales' (2000) framework on resiliency provides ideas of how this might be approached in schools: teaching students to (a) recognize challenges; (b) identify and seek out protective factors to offset a challenge; and (c) value, refine, and implement the protective factors in order to achieve future goals. Importantly, a key aspect of Morales' framework is that it is cyclical—it provides students with tools to navigate new academic challenges as they occur. As noted above, this cyclical nature was evident in our process model (Figure 4).

In order to promote academic achievement among students, we suggest direct instruction as one approach for teachers that attracts relatively large effect sizes in the literature (Hattie, 2009; Liem \& Martin, 2013). Direct instruction involves carefully planned teaching to promote systematic mastery through several specific steps (e.g., communicating learning goals, providing guided practice; Hattie, 2009; Liem \& Martin, 2013). It is thus an approach-in combination with a framework for developing buoyancy through academic protective factors - that may help teachers to spur a more positive cycle of buoyancy, achievement, and control among students. Other potential approaches include autonomy support (e.g., Jang et al., 2012) and instructional support (e.g., Pakarinen et al., 2011).

\section{Limitations and Future Directions}

There are several limitations of the current study. First, data were self-reported by students. Given that buoyancy and control are intra-psychic factors, we suggest that this approach is an appropriate one. Nonetheless, it would be interesting to explore how perceptions line up across students, teachers, and parents on the factors of interest. For achievement, we relied on students' reports of the results from standardized testing. Moreover, this achievement was based on results from standardized testing that students completed prior to completing the survey. Thus, there is a 
need for research to substantiate these findings with measures of actual achievement that are collected at the same time as the other constructs in the model. Notwithstanding this, Hattie's (2009) demonstration of self-reported prior achievement as a very strong correlate of students' actual achievement provides some support for our methods. In addition, we had actual data for a sub-sample of students that did not differ from their self-reports (see Measures).

Second, we recognize that our indirect effects are not large in absolute terms; but we also make the point that this is not unusual for indirect effects, particularly when auto-regression has been accounted for. Often when indirect effects are large, it is because auto-regression has not been controlled, thereby misleadingly inflating the size of the indirect effect (Martin, 2011). Indeed, our inclusion of numerous main effects, auto-regression, and covariates echoes something of a contextual value added (CVA) approach that seeks to take into account the circumstances and attributes of students when assessing effects (e.g., of schools and teachers). Although we have not strictly adhered to CVA modeling, the presence of significant indirect effects is notable from this perspective.

Third, in examining control as a linking mechanism we drew upon attribution theory (Weiner, 2010) which aligns well with our operationalization of control. However, there are other perspectives that may also help explain the relationship between buoyancy and achievement (e.g., primary versus secondary control; Heckhausen et al., 2010; Morling \& Evered, 2006, 2007; Skinner, 2007). Examining the influence of alternative control constructs is one potential avenue of future research. For example, our operationalized control belief was somewhat non-means-specific (Skinner et al., 1998) and so future measures of means-specific capacity beliefs (Skinner et al., 1998) might be included — as might appraisal of control in domain-specific research following previous work into the domain specificity of buoyancy in mathematics, English, science, and physical education (Malmberg, Hall, \& Martin, 2013).

Finally, we focused on control; however, this does not rule out the existence of other constructs that may also be relevant in understanding the link between buoyancy and achievement 
(e.g., see Putwain et al., 2012; Putwain \& Daly, 2013). Future work may focus on determining the extent to which control and other possible mechanisms influence how buoyancy and achievement are related. In addition, one recent conceptual development is control-value theory (Pekrun, 2006) which states that students' achievement-related emotions are a function of their control appraisals and the extent to which the achievement is subjectively important to them. Future research might therefore include valuing in the buoyancy process explored in this study. Indeed, Collie and colleagues (2014) have suggested there may not be a great relevance of buoyancy for students who have disengaged from school. That is, academic setback is not so aversive if there is little subjective valuing of the domain in which that setback occurs.

\section{Conclusions}

The present findings provide insight into the sometimes modest relationships that are found between academic buoyancy and student achievement. The findings also speak to issues of academic adversity more generally as they highlight the potential role of control in helping student setback to be transformed into subsequent positive outcomes. More broadly, the findings speak to the issue of sufficiently attending to social-emotional factors in schooling. In particular, the findings add weight to calls by various stakeholders about the importance of student social-emotional wellbeing and development in schooling for academic achievement. 


\section{References}

Bandura, A. (1989). Human agency in social cognitive theory. American Psychologist, 44, 11751184. http://dx.doi.org/10.1037/0003-066X.44.9.1175

Bandura, A. (2001). Social cognitive theory: An agentic perspective. Annual Review of Psychology, 52, 1-26. http://dx.doi.org/10.1146/annurev.psych.52.1.1

Bandura, A. (2006). Toward a psychology of human agency. Perspectives on Psychological Science, 1, 164-180. http://dx.doi.org/10.1111/j.1745-6916.2006.00011.x

Caprara, G. V., Vecchione, M., Alessandri, G., Gerbino, M., \& Barbaranelli, C. (2011). The contribution of personality traits and self-efficacy beliefs to academic achievement: A longitudinal study. British Journal of Educational Psychology, 81, 78-96. http://dx.doi.org/10.1348/2044-8279.002004

Collie, R. J., Martin, A. J., Bottrell, D., Armstrong, D., Ungar, M., \& Liebenberg, L. (2014). Social support, academic adversity, and academic buoyancy: A person-centered analysis and implications for academic outcomes. Manuscript submitted for publication.

Connell, J. P. (1985). A new multidimensional measure of children's perceptions of control. Child Development, 56, 1018-1041.

Deci, E. L., \& Ryan, R. M. (1985). Intrinsic motivation and self-determination in human behavior. New York, NY: Plenum Press.

Deci, E. L., \& Ryan, R. M. (2012). Motivation, personality, and development within embedded social contexts: An overview of self-determination theory. In R. M. Ryan (Ed.), The Oxford handbook of human motivation (pp. 85-110). New York, NY: Oxford University Press.

Durlak, J. A., Weissberg, R. P., Dymnicki, A. B., Taylor, R. D., \& Schellinger, K. B. (2011). The impact of enhancing students' social and emotional learning: A meta-analysis of school-based universal interventions. Child Development, 82, 405-432. http://dx.doi.org/10.1111/j.14678624.2010.01564.x

Dweck, C. S. (2006). Mindset: The new psychology of success. New York, NY: Random House. 
Dweck, C. S., \& Master, A. (2009). Self-theories and motivation: Students' beliefs about intelligence. In K. R. Wentzel, \& A. Wigfield (Eds.), Handbook of motivation at school (pp. 123-140). New York, NY: Routledge.

Green, J., Martin, A. J., \& Marsh, H. W. (2007). Motivation and engagement in English, mathematics and science high school subjects: Towards an understanding of multidimensional domain specificity. Learning and Individual Differences, 17, 269-279. http://dx.doi.org/10.1016/j.lindif.2006.12.003

Greenberg, M. T., Weissberg, R. P., O'Brien, M. U., Zins, J. E., Fredericks, L., Resnik, H., \& Elias, M. J. (2003). Enhancing school-based prevention and youth development through coordinated social, emotional, and academic learning. American Psychologist, 58, 466-474. http://dx.doi.org/10.1037/0003-066X.58.6-7.466

Hattie, J. (2009). Visible learning: A synthesis of over 800 meta-analyses relating to achievement. New York, NY: Routledge.

Heckhausen, J., Wrosch, C., \& Schulz, R. (2010). A motivational theory of life-span development. Psychological Review, 117, 32-60. http://dx.doi.org/10.1037/a0017668

Huck, S. W., Cormier, W. H., \& Bounds, W. G. (1974). Reading statistics and research. New York, NY: Harper and Row.

Liem, G. A. D., \& Martin, A. J. (2012). The motivation and engagement scale: Theoretical framework, psychometric properties, and applied yields. Australian Psychologist, 47, 3-13. http://dx.doi.org/10.1111/j.1742-9544.2011.00049.x

Liem, G. A. D., \& Martin, A. J. (2013). Direct instruction. In J. Hattie, \& E. M. Anderman (Eds.), International guide to student achievement (pp. 366-368). New York, NY: Routledge.

MacKinnon, D. P., Lockwood, C. M., Hoffman, J. M., West, S. G., \& Sheets, V. (2002). A comparison of methods to test mediation and other intervening variable effects. Psychological Methods, 7, 83-104. http://dx.doi.org/10.1037/1082-989X.7.1.83 
Malmberg, L-E., Hall, J., \& Martin, A. J., (2013). Academic buoyancy in secondary school: exploring patterns of convergence in mathematics, science, English and physical education. Learning and Individual Differences, 23, 262-266.

Marsh, H. W., Balla, J. R., \& Hau, K. T. (1996). An evaluation of incremental fit indices: A clarification of mathematical and empirical processes. In G. A. Marcoulides, \& R. E. Schumacker (Eds.), Advanced structural equation modelling techniques (pp. 315-353). Hillsdale, NJ: Erlbaum.

Marsh, H.W., Hau, K.-T., Artelt, C., Baumert, J., \& Peschar, J. L. (2006). OECD's brief self-report measure of educational psychology's most useful affective constructs: Cross-cultural, psychometric comparisons across 25 countries. International Journal of Testing, 6, 311-360.

Martin, A. J. (2006). Personal bests (PBs): A proposed multidimensional model and empirical analysis. British Journal of Educational Psychology, 76, 803-825.

http://dx.doi.org/10.1348/000709905X55389

Martin, A.J. (2007). Examining a multidimensional model of student motivation and engagement using a construct validation approach. British Journal of Educational Psychology, 77, 413440. http://dx.doi.org/10.1348/000709906X118036

Martin, A. J. (2010). The motivation and engagement scale. Sydney, Australia: Lifelong Achievement Group. Retrieved from www.lifelongachievement.com

Martin, A.J. (2011). Prescriptive statements and educational practice: What can Structural Equation Modeling (SEM) offer? Educational Psychology Review, 23, 235-244.

Martin, A. J. (2013). Academic buoyancy and academic resilience: Exploring 'everyday’ and 'classic' resilience in the face of academic adversity. School Psychology International, 34, 488-500. http://dx.doi.org/10.1177/0143034312472759

Martin, A. J. (2014). Academic buoyancy and academic outcomes: Towards a further understanding of students with attention-deficit/hyperactivity disorder (ADHD), students without ADHD, 
and academic buoyancy itself. British Journal of Educational Psychology, 84, 86-107. http://dx.doi.org/10.1111/bjep.12007

Martin, A.J. (in press). Implicit theories about intelligence and growth (personal best) goals: Exploring reciprocal relationships. British Journal of Educational Psychology.

Martin, A. J., Colmar, S. H., Davey, L. A., \& Marsh, H. W. (2010). Longitudinal modelling of academic buoyancy and motivation: Do the 5Cs hold up over time? British Journal of Educational Psychology, 80, 473-496. http://dx.doi.org/10.1348/000709910X486376

Martin, A. J., Ginns, P., Brackett, M. A., Malmberg, L., \& Hall, J. (2013). Academic buoyancy and psychological risk: Exploring reciprocal relationships. Learning and Individual Differences, 27, 128-133. http://dx.doi.org/10.1016/j.lindif.2013.06.006

Martin, A. J., \& Marsh, H. W. (2006). Academic resilience and its psychological and educational correlates: A construct validity approach. Psychology in the Schools, 43, 267-281. http://dx.doi.org/10.1002/pits.20149

Martin, A. J., \& Marsh, H. W. (2008). Academic buoyancy: Towards an understanding of students' everyday academic resilience. Journal of School Psychology, 46, 53-83. http://dx.doi.org/10.1016/j.jsp.2007.01.002

Martin, A. J., \& Marsh, H. W. (2009). Academic resilience and academic buoyancy: Multidimensional and hierarchical conceptual framing of causes, correlates and cognate constructs. Oxford Review of Education, 35, 353-370. http://dx.doi.org/10.1080/03054980902934639

Martin, A.J., Nejad, H.G., Colmar, S., \& Liem, G.A.D. (2013). Adaptability: How students' responses to uncertainty and novelty predict their academic and non-academic outcomes. Journal of Educational Psychology, 105, 728-746. http://dx.doi.org/10.1037/a0032794 Martin, A.J. Papworth, B., Ginns, P., \& Liem, G.A.D. (2014). Boarding school, motivation and engagement, and psychological well-being: A large-scale investigation. American Educational Research Journal. http://dx.doi.org/10.3102/0002831214532164 
McDonald, R. P., \& Marsh, H. W. (1990). Choosing a multivariate model: Noncentrality and goodness-of-fit. Psychological Bulletin, 107, 247-255.

Morales, E. E. (2000). A contextual understanding of the process of educational resilience: High achieving Dominican American students and the "resilience cycle". Innovative Higher Education, 25, 7-22. http://dx.doi.org/10.1023/A:1007580217973

Morling, B., \& Evered, S. (2006). Secondary control reviewed and defined. Psychological Bulletin, 132, 269-296. http://dx.doi.org/10.1037/0033-2909.132.2.269

Morling, B., \& Evered, S. (2007). The construct formerly known as secondary control: Reply to Skinner (2007). Psychological Bulletin, 133, 917-919. http://dx.doi.org/10.1037/00332909.133.6.917

Muthén, L. K., \& Muthén, B. O. (2012). Mplus user's guide (7th ed.). Los Angeles, CA: Muthén \& Muthén.

Nagabhushan, P. (2013). Academic motivation and engagement: An examination of its factor structure in senior school years. European Journal of Social and Behavioural Sciences, eISSN: $2301-2218$

Pekrun, R. (2006). The control-value theory of achievement emotions: Assumptions, corollaries, and implications for educational research and practice. Educational Psychology Review, 18, 315-241. http://dx.doi.org/10.1007/s10648-006-9029-9

Pekrun, R., Goetz, T., Frenzel, A. C., Barchfeld, P., \& Perry, R. P. (2011). Measuring emotions in st he achievement emotions questionnaire (AEQ).

Contemporary Educational Psychology, 36, 36-48.

http://dx.doi.org/10.1016/j.cedpsych.2010.10.002

Plenty, S., \& Heubeck, B. G. (2011). Mathematics motivation and engagement: An independent evaluation of a complex model with Australian rural high school students. Educational Research and Evaluation, 17, 283-299. http://dx.doi.org/10.1080/13803611.2011.622504 
Plenty, S., \& Heubeck, B. G. (2013). A multidimensional analysis of changes in mathematics motivation and engagement during high school. Educational Psychology, 33, 14-30. http://dx.doi.org/10.1080/01443410.2012.740199

Putwain, D. W., Connors, L., Symes, W., \& Douglas-Osborn, E. (2012). Is academic buoyancy anything more than adaptive coping? Anxiety, Stress, \& Coping, 25, 349-358. http://dx.doi.org/10.1080/10615806.2011.582459

Putwain, D. W., \& Daly, A. L. (2013). Do clusters of test anxiety and academic buoyancy differentially predict academic performance? Learning and Individual Differences, 27, 157162. http://dx.doi.org/10.1016/j.lindif.2013.07.010

Reeve, J., \& Jang, H. (2006). What teachers say and do to support students' autonomy during a learning activity. Journal of Educational Psychology, 98, 209-218. http://dx.doi.org/10.1037/0022-0663.98.1.209

Ross, C. E., \& Broh, B. A. (2000). The roles of self-esteem and the sense of personal control in the academic achievement process. Sociology of Education, 73, 270-284. http://dx.doi.org/10.2307/2673234

Ryan, R. M., \& Deci, E. L. (2000). The darker and brighter sides of human existence: Basic psychological needs as a unifying concept. Psychological Inquiry, 11, 319-338. http://dx.doi.org/10.1207/S15327965PLI1104_03

Skinner, E. A. (1996). A guide to constructs of control. Journal of Personality and Social Psychology, 71, 549-570. http://dx.doi.org/10.1037/0022-3514.71.3.549

Skinner, E. A. (2007). Secondary control critiqued: Is it secondary? Is it control? Comment on Morling and Evered (2006). Psychological Bulletin, 133, 911-916. http://dx.doi.org/10.1037/0033-2909.133.6.911

Skinner, E. A., Zimmer-Gembeck, M., \& Connell, J. P. (1998). Individual differences and the development of perceived control. Monographs of the Society for Research in Child Development, 63, v-220. http://dx.doi.org/10.2307/1166220 
Skinner, E. A., Wellborn, J. G., \& Connell, J. P. (1990). What it takes to do well in school and whether I've got it: A process model of perceived control and children's engagement and achievement in school. Journal of Educational Psychology, 82, 22-32. http://dx.doi.org/10.1037/0022-0663.82.1.22

Weiner, B. (2010). The development of an attribution-based theory of motivation: A history of ideas. Educational Psychologist, 45, 28-36. http://dx.doi.org/ 10.1080/00461520903433596

You, S., Hong, S., \& Ho, H. (2011). Longitudinal effects of perceived control on academic achievement. Journal of Educational Research, 104, 253-266.

http://dx.doi.org/10.1080/00220671003733807 
Table 1

Descriptive Statistics, Factor Loadings, and Cronbach's Alphas

\begin{tabular}{|c|c|c|c|c|c|c|}
\hline Time 1 & Min & Max & $\mathrm{M} / \%$ & SD & $\begin{array}{c}\text { Factor } \\
\text { loading }\end{array}$ & $\begin{array}{c}\text { Cronbach's } \\
\text { alpha }\end{array}$ \\
\hline Social economic status & 712 & 1214 & 1026.39 & 92.28 & 1.00 & \\
\hline Mother's education & 1 & 6 & 4.65 & 1.55 & 0.65 & \\
\hline Father's education & 1 & 6 & 4.64 & 1.56 & 0.83 & \\
\hline Language background $^{a}$ & 0 & 1 & 0.10 & & 1.00 & \\
\hline Gender $^{b}$ & 0 & 1 & $52.4 \%$ & & 1.00 & \\
\hline Age & 11 & 18 & 13.84 & 1.29 & 1.00 & \\
\hline Academic buoyancy & & & & & & .80 \\
\hline Item 1 & 1 & 7 & 4.54 & 1.72 & 0.65 & \\
\hline Item 2 & 1 & 7 & 4.76 & 1.46 & 0.69 & \\
\hline Item 3 & 1 & 7 & 4.73 & 1.57 & 0.74 & \\
\hline Item 4 & 1 & 7 & 4.75 & 1.48 & 0.78 & \\
\hline Academic achievement & & & & & & .82 \\
\hline Literacy & 1 & 10 & 7.35 & 1.77 & 0.81 & \\
\hline Numeracy & 1 & 10 & 7.31 & 1.85 & 0.87 & \\
\hline Control belief & & & & & & .77 \\
\hline Item 1 & 1 & 7 & 3.57 & 1.66 & 0.62 & \\
\hline Item 2 & 1 & 7 & 3.39 & 1.73 & 0.63 & \\
\hline Item 3 & 1 & 7 & 3.34 & 1.74 & 0.75 & \\
\hline Item 4 & 1 & 7 & 2.95 & 1.62 & 0.73 & \\
\hline \multicolumn{7}{|l|}{ Time 2} \\
\hline Academic buoyancy & & & & & & .79 \\
\hline Item 1 & 1 & 7 & 4.42 & 1.72 & 0.63 & \\
\hline Item 2 & 1 & 7 & 4.74 & 1.47 & 0.71 & \\
\hline Item 3 & 1 & 7 & 4.56 & 1.59 & 0.70 & \\
\hline Item 4 & 1 & 7 & 4.65 & 1.52 & 0.77 & \\
\hline Academic achievement & & & & & & .81 \\
\hline Literacy & 2 & 10 & 7.73 & 1.69 & 0.80 & \\
\hline Numeracy & 1 & 10 & 7.68 & 1.81 & 0.87 & \\
\hline Control belief & & & & & & .81 \\
\hline Item 1 & 1 & 7 & 3.48 & 1.61 & 0.65 & \\
\hline Item 2 & 1 & 7 & 3.41 & 1.73 & 0.71 & \\
\hline Item 3 & 1 & 7 & 3.21 & 1.68 & 0.76 & \\
\hline Item 4 & 1 & 7 & 2.89 & 1.57 & 0.77 & \\
\hline
\end{tabular}


Table 2

\section{Latent and Raw Correlations}

\begin{tabular}{|c|c|c|c|c|c|c|c|c|c|c|c|}
\hline & 1. & 2. & 3. & 4. & 5. & 6. & 7. & 8. & 9. & 10. & 11. \\
\hline 1. Social economic status & & .33 & .07 & .04 & -.08 & .02 & .15 & -.13 & .04 & .20 & -.12 \\
\hline 2. Parent's education & .38 & & .02 & .08 & -.02 & .06 & .23 & -.15 & .06 & .27 & -.14 \\
\hline 3. Language background & .07 & .04 & & .01 & -.02 & .02 & .06 & .03 & .03 & .08 & .02 \\
\hline 4. Gender & .04 & .10 & .01 & & .07 & .15 & .06 & -.01 & .15 & .07 & .04 \\
\hline 5. Age & -.07 & -.02 & -.03 & .07 & & -.13 & .10 & .02 & -.09 & .07 & .06 \\
\hline 6. T1 Academic buoyancy & .01 & .09 & .01 & .16 & -.14 & & .10 & -.32 & .49 & .10 & -.23 \\
\hline 7. T1 Achievement & .15 & .29 & .07 & .08 & .12 & .13 & & -.29 & .09 & .62 & -.25 \\
\hline 8. T1 Control & -.14 & -.19 & .03 & -.01 & .02 & -.40 & -.35 & & -.22 & -.29 & .48 \\
\hline 9. T2 Buoyancy & .05 & .08 & .03 & .15 & -.10 & .59 & .12 & -.28 & & .13 & -.31 \\
\hline 10. T2 Achievement & .20 & .36 & .08 & .09 & .09 & .11 & .64 & -.37 & .16 & & -.29 \\
\hline 11. T2 Control & -.13 & -.19 & .01 & .05 & .06 & -.28 & -.30 & .59 & -.39 & -.35 & \\
\hline
\end{tabular}

Note. Latent correlations in lower triangle and raw (pairwise $n \mathrm{~s}=1951$ to 2791) correlations in upper triangle. 


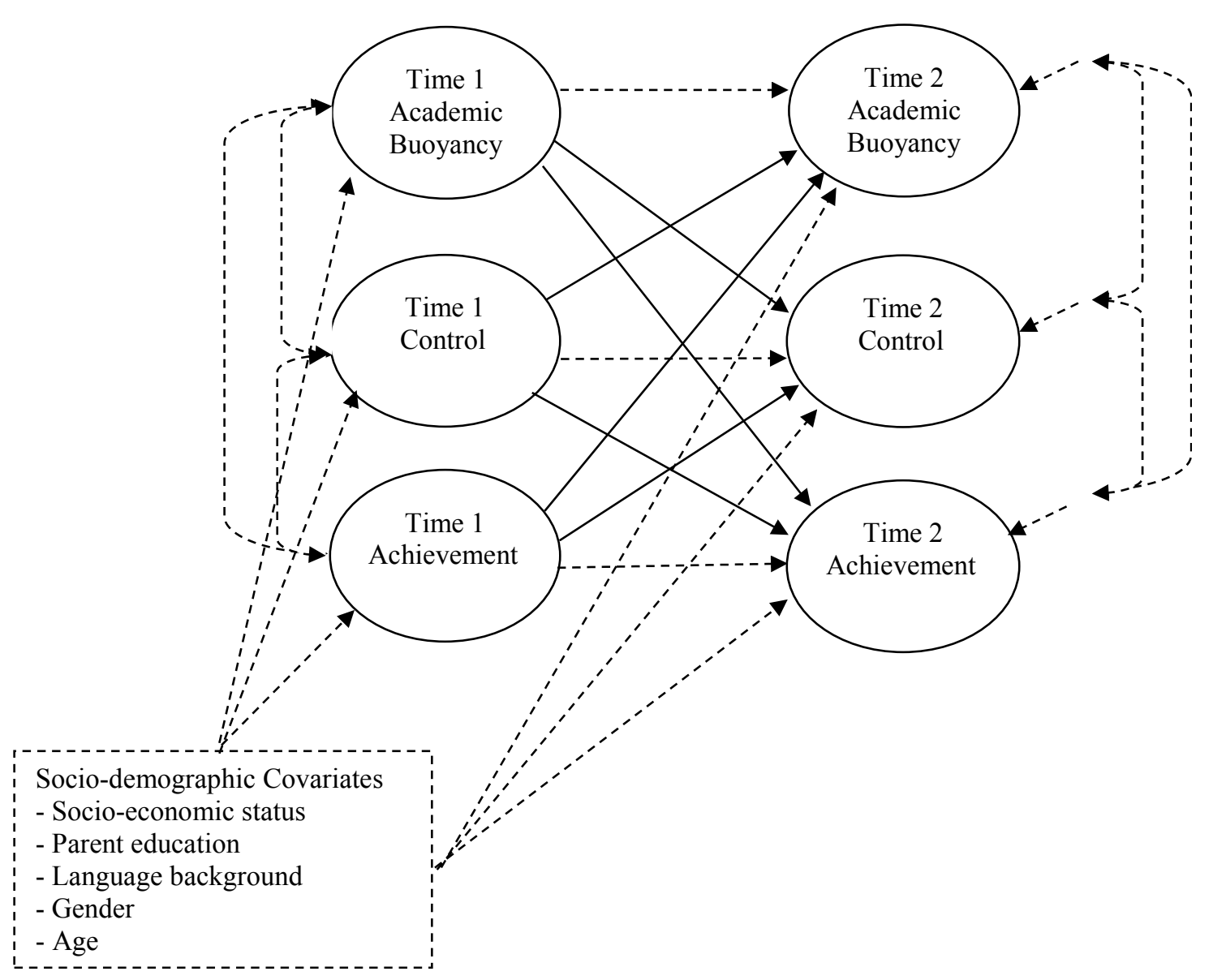

Figure 1. Hypothesized cross-lagged relationships between academic buoyancy, control, and achievement. Bolded single-headed arrows represent cross-lagged path coefficients; dashed lines represent auto-lagged path coefficients, residuals, or covariate parameters; double-headed arrows represent unlagged correlation coefficients. 


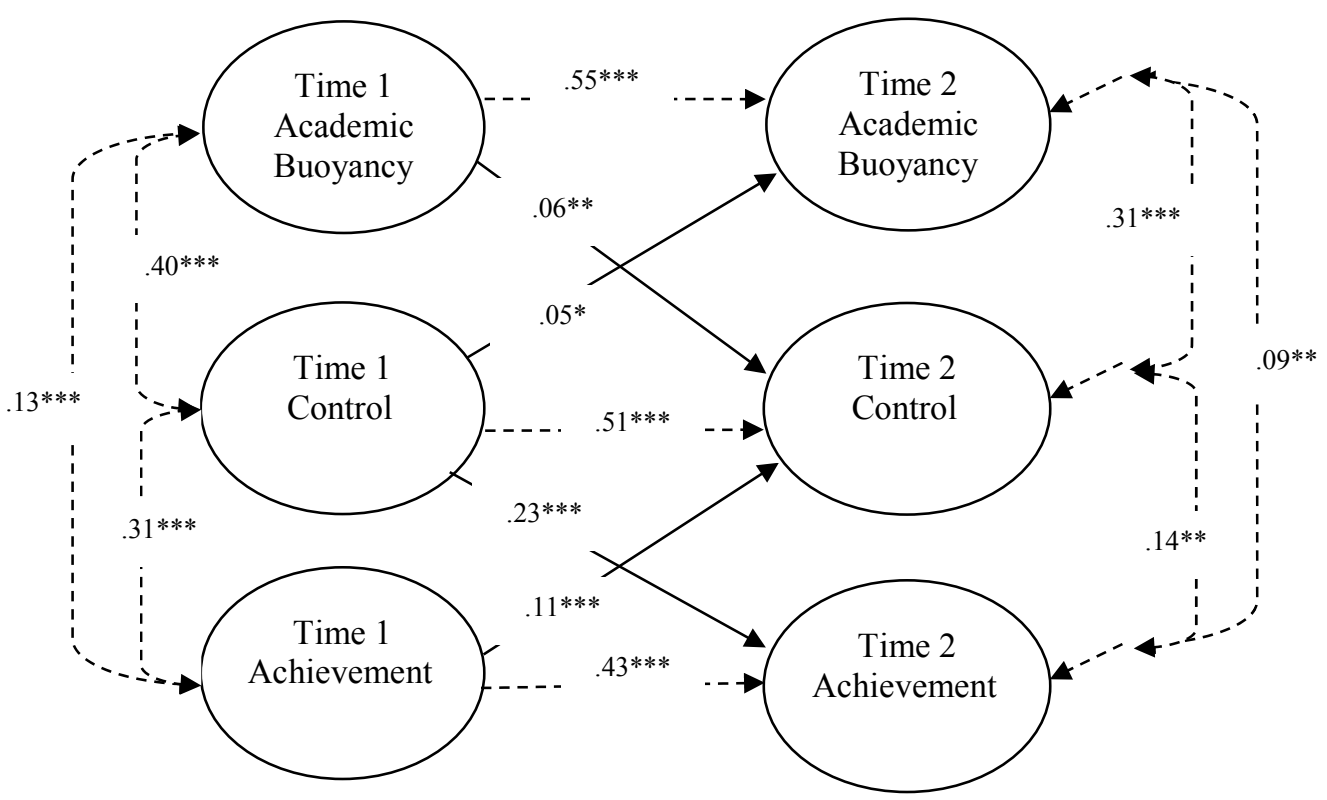

Figure 2. Cross-lagged relationships between academic buoyancy, control, and achievement (controlling for socio-economic status, parent education, language background, gender, age). Model fit: $\chi^{2}=1053.54, d f=238$, CFI $=.96$, RMSEA $=.034$. 


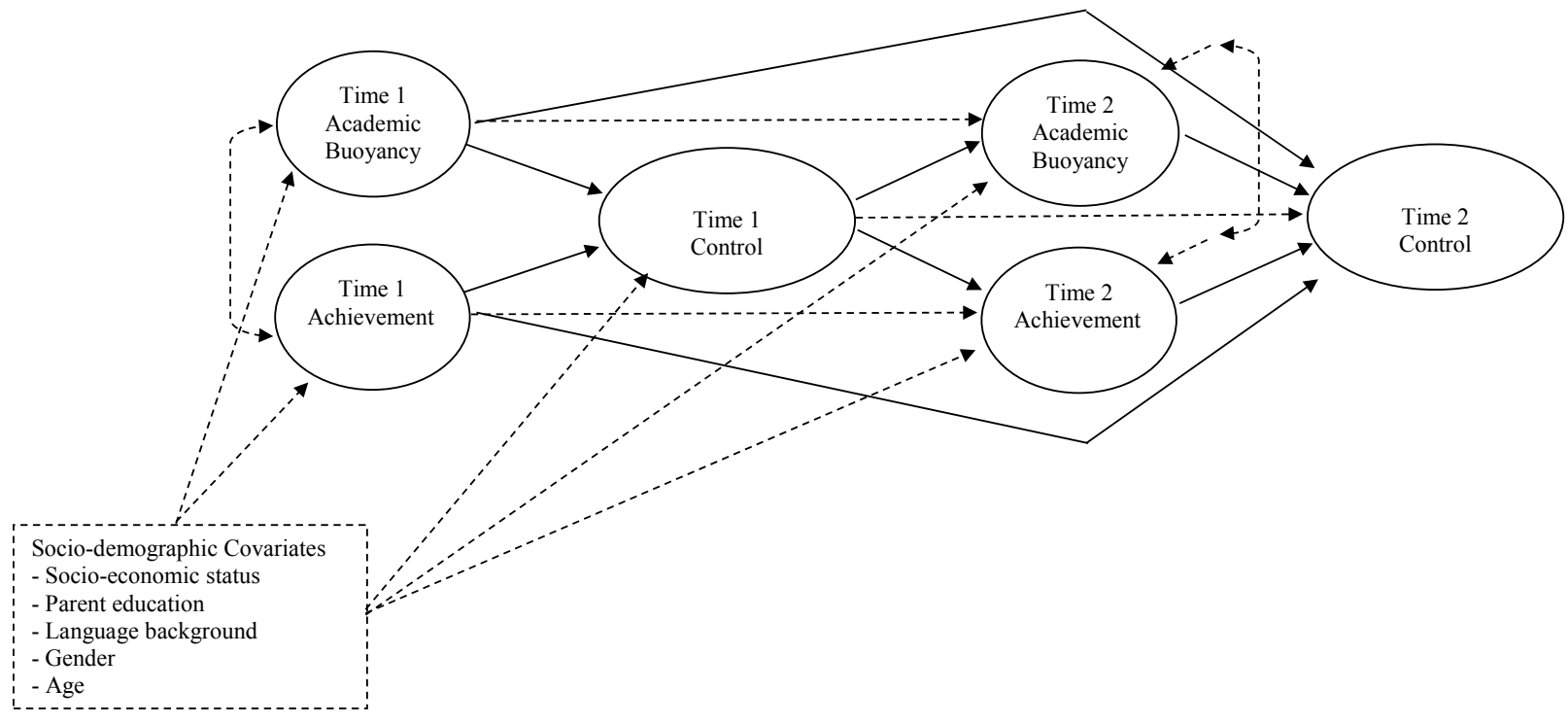

Figure 3. Hypothesized process model between academic buoyancy, control, and achievement. Bolded single-headed arrows represent cross-lagged path coefficients; dashed lines represent auto-lagged path coefficients, residuals, or covariate parameters; double-headed arrows represent unlagged correlation coefficients. 


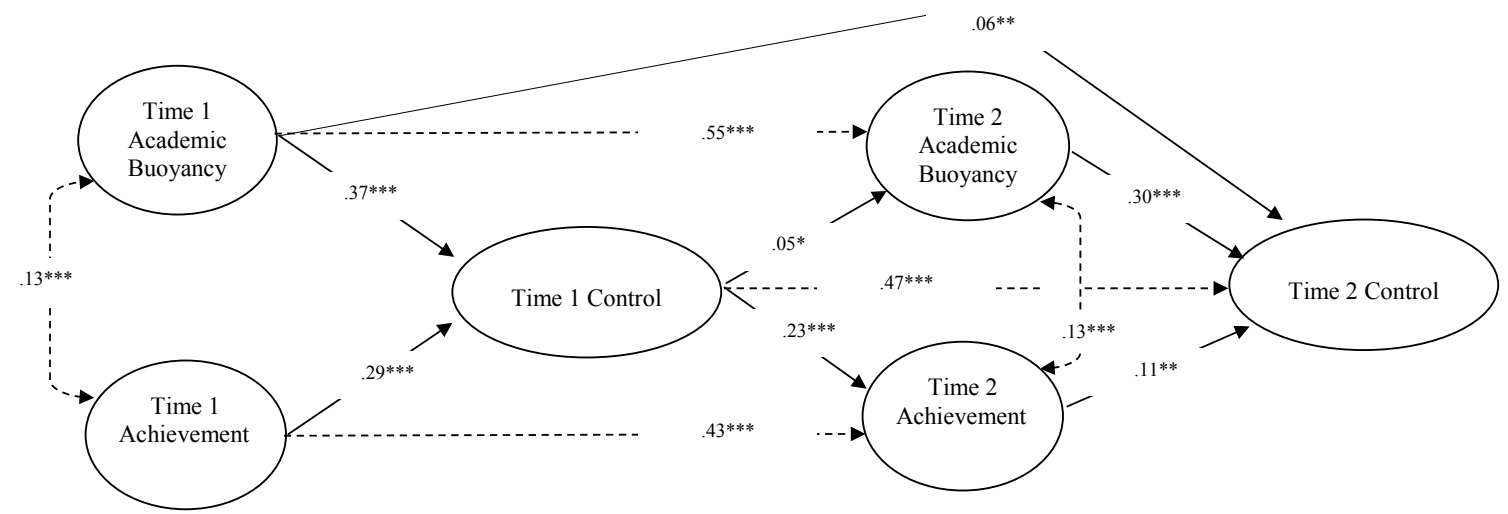

Bootstrapping (Indirect Effects)

Indirect Path from T1 Achievement to T2 Buoyancy, via T1 Control, $\beta=.02, p<.01$

Indirect Path from T1 Buoyancy to T2 Achievement, via T1 Control, $\beta=.08, p<.001$

Indirect Path from T1 Achievement to T2 Achievement, via T1 Control, $\beta=.06, p<.001$

Indirect Path from T1 Buoyancy to T2 Buoyancy, via T1 Control, $\beta=.02, p<.01$

Indirect Path from T1 Control to T2 Control, via T2 Buoyancy, $\beta=02, p<01$

Indirect Path from T1 Control to T2 Control, via T2 Achievement, $\beta=.04, p<.00$

Figure 4. Standardized betas for process model between academic buoyancy, control, and achievement (controlling for socio-economic status, parent education, language background, gender, age). Model fit: $\chi^{2}=1053.54, d f=238, \mathrm{CFI}=.96, \mathrm{RMSEA}=.034$. 